\title{
ROLE OF THE SYMPATHETIC IN LACRIMAL SECRETION*
}

\author{
BY \\ JOHN WHITWELL \\ Bournemouth
}

THE lacrimal gland is innervated by the lacrimal, the facial, and the cervical sympathetic nerves; the anatomical and functional characteristics of each were briefly summarized in a previous communication (Whitwell, 1958). Overwhelming evidence points to the fact that the lacrimal nerve is not secretory in function, but is purely the afferent path of a reflex arc. Similarly, the facial nerve is of prime importance in the control of lacrimation, especially the reflex tear secretion. Nevertheless, in clinical cases of complete paralysis of the facial or greater superficial petrosal nerves, although weeping is abolished, the eye remains comfortably moist (Rowbotham, 1939). The problem of the residual secretion remains undecided. It is possible that the completely denervated gland autonomously secretes a constant small amount of tears, or that a blood hormone is the stimulating factor. It is equally possible that the sympathetic nervous system is responsible.

The literature on the role of the sympathetic in tear secretion is both contradictory and confusing. Herzenstein (1868) cut the cervical sympathetic in dogs and noticed no alteration in tear secretion, as also when he stimulated the upper cut end. Wolferz (1871) in dogs, and Demtschenko (1871) and Laffay (1896) in rabbits, all obtained lacrimation on stimulation of the cervical sympathetic, even after section of the lacrimal nerves. Tepliachine (1894) obtained similar results. In a detailed study, Reich (1873) stimulated the distal end of the cut cervical sympathetic. In five rabbits, increased lacrimation was noticed, but in four there was no effect. In seven rabbits, removal of the superior cervical ganglion had no effect on the reflex lacrimation caused by nasal mustard-oil stimulation. In six rabbits, after removal of both superior cervical ganglia and the trigeminal on one side, it was still possible to obtain reflex lacrimation.

Experimenting on monkeys, Campos (1897) noticed no effect by stimulating the cervical sympathetic. Vulpian (1875) found that section of the cervical sympathetic or removal of the superior cervical ganglion of cats and dogs may give an increased tear secretion, but not constantly. In some dogs, curarized and under artificial respiration, removal of the left superior cervical ganglion caused a more abundant secretion from the right eye. In

\footnotetext{
* Received for publication October 4, 1960.
} 
his experiments on rabbits, Laffay (1896) found that stimulation of the cervical sympathetic produced no hypersecretion when the facial nerve had been extirpated a few weeks previously.

Schirmer (1909), in an excellent review, suggested that conjunctival and lid hyperaemia caused by sympathectomy reflexly caused the lacrimal secretion in many of the earlier animal experiments - a view already put forward by Levinsohn (1903), who had found that sympathetic section in man induced a secretion of tears. Schirmer stimulated the peripheral end of the cut cervical sympathetic in a human undergoing cervical sympathectomy with negative results. In old sympathetic lesions, he noticed no alteration in the quality or the quantity of the tears, but in fresh sympathectomies, the secretion was reduced. Apart from this evidence on fresh sympathectomies, most clinical observations show that unilateral cervical sympathetic lesions (surgical or pathological) have no effect on lacrimal secretion (Mutch, 1944; Campos, 1897; Schirmer, 1909).

It will be seen that, although Schirmer (1909), Whitnall (1932) and DukeElder (1938), believe the sympathetic to be secretory in function, the experimental and clinical evidence is not altogether convincing.

This confusing literature leads one to agree with Schirmer that further animal experiments would be unlikely to furnish any more useful information, and that only observations on humans offer much hope of further advances in knowledge.

\section{Present Investigations}

However, an opportunity presented itself at the Institute of Ophthalmology to stimulate the cervical sympathetic of a cat. The cat was anaesthetized with Nembutal, and Mr. D. P. Greaves, to whom I am indebted, had dissected out both cervical sympathetic chains for work on intra-ocular pressure.

Observation 1.-The left cervical sympathetic was stimulated at roughly the mid-point by a double electrode (Faradic current, $2 \mathrm{~V}, 30$ c.p.s.) for 4 minutes, with Schirmer-type filter paper in each conjunctival sac in the usual manner. The level of tear secretion was marked off after 1 minute and again after 4 minutes, and recorded in millimetres. The electrical current was accompanied by extreme dilatation of the left pupil and retraction of the nictitating membrane.

\begin{tabular}{c|c|c}
\hline \multirow{2}{*}{ Schirmer Reading } & \multicolumn{2}{|c}{ Eye } \\
\cline { 2 - 3 } & Right & Left \\
\hline 1 min. & 2 & 5 \\
\hline 4 min. & 6 & $6 \frac{1}{2}$ \\
\hline
\end{tabular}


The results show that stimulation of the cervical sympathetic causes an immediate increase of lacrimation, but that after an interval of continued stimulation, the secretion becomes almost equal on the two sides. Harder's gland is a direct posterior relation of, and indeed is closely attached to the nictitating membrane, and the most plausible explanation of this result is that the strong retraction of the membrane expresses the secretion of Harder's gland to provide the apparent fleeting hypersecretion. This view is submitted as a possible explanation of some of the diverse results found in earlier animal experiments. For instance, Arloing (1890) and Levinsohn (1903) reported that a few minutes after the resection of the cervical sympathetic, the corresponding eye is filled with tears.

The cervical sympathetic has been stimulated at operation in two cases in humans.

Observation 2.-A man aged 56 had had a left cervical sympathectomy performed for a disciform degeneration of the maculae. Before excision of a length of the chain above the stellate ganglion, it was stimulated by a double electrode (Faradic current, 4 V, 25 c.p.s.) for a period of 5 minutes. Schirmer's test was carried out pre-operatively and also during the time of excitation.

\begin{tabular}{c|c|c}
\hline \multirow{2}{*}{ Schirmer Reading (5 min.) } & \multicolumn{2}{|c}{ Eye } \\
\cline { 2 - 3 } & Right & Left \\
\hline Pre-operative & 13 & 13 \\
\hline During Excitation & 0 & 0 \\
\hline
\end{tabular}

However, shortly after the above observation, an important paper by Rutherford (1913) came to notice. In describing the tear secretion as a guide to anaesthesia, he states that the eye becomes quite dry in the 3rd and 4th stages. No explanation of this phenomenon is offered and it is not known whether the paralysis of the gland is a local one (poisoning of the gland itself) or a central nervous one. In the former case, stimulation of the secreto-motor nerve would be without effect, in the latter case, secretion would occur. The latter explanation would seem the more likely, but on the other hand, such an experienced surgeon as Rowbotham (1939) stimulated the greater superficial petrosal nerve on two occasions with a Faradic battery and was unable to produce tears. Presumably the patient was in the third stage of anaesthesia.

Observation 3.-A right sympathectomy was being performed on a female aged 22 for Raynaud's disease. The surgeon was able to stimulate the cervical sympathetic above the stellate ganglion as in the previous observation. The level 
of anaesthesia (gas, oxygen, and ether) was reduced to as low a level as possible at the time of stimulation. The Schirmer reading was $1 \mathrm{~mm}$. in each eye.

In both these observations, sympathetic stimulation was accompanied by marked dilatation of the pupil. The results obtained are in full agreement with those of Schirmer himself and of Axenfeld, both of whom obtained negative results on sympathetic stimulation in man at operation.

In the case of the subject of Observation 2 the sympathectomy on the right side was delayed for several weeks and other tests were performed in the meantime.

Observation 4. -13 days after the first operation, an ordinary Schirmer test was performed. After an interval, the test was repeated, but for only one minute, and the patient was asked to sniff strong ammonia. Although the standard Schirmer test, by reason of the conjunctival foreign body, mainly measures reflex lacrimation, the ammonia strongly increases this reflex tearing. After a further interval, 1 per cent. amethocaine was instilled into both eyes, and after another 5 minutes the Schirmer test was repeated in a completely darkened room. The object of this was to remove all reflex stimuli to tear secretion.

\begin{tabular}{c|c|c}
\hline \multirow{2}{*}{ Test } & \multicolumn{2}{|c}{ Eye } \\
\cline { 2 - 3 } & Right & Left \\
\hline Standard Schirmer (5 min.) & 13 & 18 \\
\hline Schirmer + Ammonia (1 min.) & 8 & 20 \\
\hline Schirmer + Amethocaine + Dark (5 min.) & 8 & $5 \frac{1}{2}$ \\
\hline
\end{tabular}

The result was so surprising that the investigation was repeated 16 days later. At the time of the first test the subject had complained that the left eye became blood-shot and watered more than the right, but there were now no subjective sensations in the eye.

\begin{tabular}{c|c|c}
\hline \multirow{2}{*}{ Test } & \multicolumn{2}{|c}{ Eye } \\
\cline { 2 - 3 } & Right & Left \\
\hline Standard Schirmer (5 min.) & 7 & 23 \\
\hline Schirmer + Ammonia (1 min.) & 15 & 17 \\
\hline Schirmer + Amethocaine + Dark (5 min.) & 8 & 4 \\
\hline
\end{tabular}

Clinically, the patient had a left Horner's syndrome, with the left pupil smaller than the right, although the ptosis was hardly noticeable. To confirm complete paresis of the cervical sympathetic, a sweating test using 
Quinizarin powder slightly modified from Guttmann (1940, 1941, 1947) showed absence of sweating on the left side of the face and neck.

The results of these tests are very unexpected, but seem capable of explanation by the phenomenon of sensitization.

Philipeaux and Vulpian (1863) observed that, after section and degeneration of the hypoglossal nerve, stimulation of the chorda tympani going to the tongue caused vasodilatation, together with a peculiar slow and prolonged contraction of the lingual muscles (the Vulpian effect). Normally, only vasodilatation is produced. This effect is thought to be due to the liberation of acetylcholine. Rogowicz (1885) found that, after section and degeneration of the facial nerve, stimulation of the cervical sympathetic caused not only a dilatation of the vessels of the gums and lips but also a contraction of the muscles of the upper lip. Langley (1901), studying the secretion of tears after the injection of adrenaline, noticed that tear production was markedly greater on the side where the superior cervical ganglion had been removed days previously. Pre-ganglionic sympathetic denervation of the nictitating membrane allows it to become gradually sensitized to adrenaline (Rosenblueth and Cannon, 1936), and section of the chorda tympani sensitizes the submaxillary gland to pilocarpine (Pierce and Gregersen, 1937). In a most interesting paper, Maes (1938) described the effects of various drugs on the lacrimal gland. Intravenous pilocarpine always gives a marked secretion, whereas adrenaline and acetylcholine give a definite increase only in very large doses. After unilateral removal of a superior cervical ganglion, the effect of drugs depends on the interval of time after the operation. Immediately afterwards, the effect is unaltered, but from 11 days up to 8 weeks after, all of these drugs cause a marked excess of tears; the results are variable, depending on the depth of anaesthesia. Removal of the adrenal medulla has no effect on this result.

In the experiment of Maes the sympathectomy was post-ganglionic, and it may be wondered if these results are applicable to the subject of Observations 2 and 4, in whom the sympathectomy was pre-ganglionic. However, a pre-ganglionic section allowed the nictitating membrane to become sensitized (Langley) and the chorda tympani section of Pierce and Gregersen was pre-ganglionic.

In explanation of Observation 4, tested 13 and 29 days after a left-sided pre-ganglionic cervical sympathectomy, it is suggested that the ordinary Schirmer test provoking a reflex lacrimal secretion through secretion of acetylcholine at the VIIth nerve terminals shows an increased secretion on the left side owing to the sensitization of the gland. This is even more enhanced by the inhalation of ammonia. When the test was repeated in the dark and with the cornea and conjunctiva effectively anaesthetized, reflex lacrimation was abolished and there was presumably no secretion of acetylcholine; tear secretion was reduced on the side of the sympathectomy. If this reduction is significant, it is difficult to explain without concluding 
that the sympathetic has some secreto-motor effect. It will be remembered that Maes and Langley found that adrenaline, albeit in large doses, caused a definite increase in lacrimation. It could be imagined that, secreted by the sympathetic terminals and associated with a local vasospasm, a sufficiently high concentration could be built up in the lacrimal gland, a level equivalent to the doses of Maes and Langley who administered the drug intravenously.

Observation 5.-A Schirmer test was performed in the usual way on a man, aged 39 , who had recently had a right dacryocystorhinostomy. By means of a technique previously described (Whitwell, 1958), the facial secromotor fibres to both lacrimal glands were blocked with 2 per cent. Xylocaine. Into each conjunctival sac was instilled a drop of 0.25 per cent. amethocaine. After 5 minutes the Schirmer test was repeated. Two injections were then prepared:

(1) 3 minims 1-1,000 adrenaline made up to $1 \mathrm{ml}$. with "Wydase" (a stable preparation of hyaluronidase).

(2) 3 minims normal saline made up to $1 \mathrm{ml}$. with "Wydase".

A point was chosen just under the supra-orbital margin judged to be in the middle of the lacrimal gland and an injection made into the substance of the gland, inserting the needle in three directions to divide the quantity of fluid as evenly as possible over the whole gland. The first injection was made into the left gland, and second into the right; 3 minutes later, Schirmer tests were repeated.

\begin{tabular}{c|c|c}
\hline \multirow{2}{*}{ Schirmer Test } & \multicolumn{2}{|c}{ Eye } \\
\cline { 2 - 3 } & Right & Left \\
\hline Initial test & 17 & 17 \\
\hline After VIIth nerve block & 3 & 3 \\
\hline After adrenaline injection to left gland & 2 & 20 \\
\hline
\end{tabular}

Observation 6. - The above experiment was repeated on the subject of Observations 2 and 4, about 6 months after his right and left cervical sympathectomies. The technique was identical to that described in Observation 5, except that the adrenaline injection was made into the right gland and the control injection into the left gland. The results are recorded below:

\begin{tabular}{c|c|c}
\hline \multirow{2}{*}{ Schirmer Test (5 min.) } & \multicolumn{2}{|c}{ Eye } \\
\cline { 2 - 3 } & Right & Left \\
\hline Initial test & 14 & 25 \\
\hline After VIIth nerve block & 3 & 0 \\
\hline After adrenaline injection to right gland & 11 & 3 \\
\hline
\end{tabular}




\section{Conclusion}

In deciding to use humans rather than animals for such a study as this, one often has to wait some time for patients that are both clinically and morally suitable; hence the small number of experiments.

To summarize the results, the single observation on the cat suggests that the proximity of Harder's gland to the nictitating membrane may well explain the diverse results found in the older literature on the subject, and the effects of general anaesthesia on tear secretion probably added to the confusion. However, the work on subject 1 and the effects of adrenaline injection into the denervated lacrimal gland show quite positive results, and one Schirmer test performed after cervical sympathectomy and blockage of VIIth nerve fibres showed no lacrimal secretion over a period of 5 minutes.

It must be admitted that these investigations were started in order to show that the cervical sympathetic is of no significance in tear secretion; the results do not justify this early misconception, but confirm the opinion of Duke-Elder (1938) that the sympathetic is responsible for the general level of tear secretion and the facial nerve for reflex excess lacrimation. After denervation of the lacrimal gland (Whitwell, 1958), the sympathetic fibres accompanying the lacrimal artery are unharmed and would continue to provide a certain (albeit reduced) level of tear secretion, maintaining a comfortably moist eye.

This work was done at the Institute of Ophthalmology and The London Hospital. The patients were under the care of Mr. A. Lister, who gave every help and encouragement. Mr. V. S. Elbogen patiently spent many hours in helping with the translation of the literature. Above all, I should like to thank the patients, who so stoically co-operated in the finest wartime tradition of the Whitechapel district.

\section{REFERENCES}

Arlonng, S. (1890). Arch. Physiol. norm. path., 5 sér., 2, 1.

CAMPOS (1897). Arch. Ophtal., 17, 529.

Demtschenko (1871). Dissertation, Petersburg. (Cited by Campos, 1897.)

Duke-Elder, S. (1938). "Text-book of Ophthalmology", vol. 1, p. 651. Kimpton, London.

Guttmann, L. (1940). J. Neurol. Psychiat., 3, 197. (1941). Proc. roy. Soc. Med., 35, 77

- (1947). Postgrad. med. J., 23, 353.

Herzenstein, U. (1868). "Beiträge zur Physiologie und Therapie der Thränenorgane". Berlin.

LAFFAY, A. (1896). Thèse, Bordeaux.

LANGley, J. N. (1901). J. Physiol. (Lond.), 27, 237.

LEVINSOHN, G. (1903). v. Graefes Arch. Ophthal., 55, 144.

MAES, J. P. (1938). Amer. J. Physiol., 123, 359.

MuTCH, J. R. (1944). Brit. J. Ophthal., 28, 317.

Philipeaux, J. M., and Vulpian, A. (1863). C.R. Acad. Sci. (Paris), 56, 1009.

Pierce, F. R., and Gregersen, M. I. (1937). Amer. J. Physiol., 120, 246.

ReICH, M. (1873). v. Graefes Arch. Ophthal., 19, pt. 3, p. 38.

Rogowicz, N. (1885). Pflüg. Arch. ges. Physiol., 36, 1.

Rosenblueth, A., and Cannon, W. B. (1936). Amer. J. Physiol., 116, 414.

RowBothaM, G. F. (1939). Brain, 62, 364.

RUTHERFORD, L. T. (1913). Brit. med. J., 1, 1313.

SCHIRmer, O. (1909). Pflüg. Arch. ges. Physiol., 126, 351.

TEPLIACHINe (1894). Arch. Ophthal., 14, 401.

VulPIAN, A. (1875). "Leçons sur l'appareil vaso-moteur”, vol. 1, p. 92. Baillière, Paris.

Whitnall, S. E. (1932). "The Anatomy of the Human Orbit", 2nd ed. O.U.P., London.

WhITWELl, J. (1958). Brit. J. Ophthal., 42, 518.

WOLFERZ, R. (1871). Dissertation, Dorpat. 